\title{
A institucionalização do ensino do jornalismo em Portugal (1941-1979): a criação da primeira Licenciatura em Comunicação Sociali
}

\begin{abstract}
Renato Rocha Mendes
Universidade Nova de Lisboa - rmendes.mailbox@gmail.com Jornalista brasileiro, correspondente em Lisboa. É doutorando em Ciências da Comunicação pela Universidade Nova de Lisboa, mesma instituição onde concluiu o mestrado em Ciências da Comunicação - Estudo dos Media e Jornalismo. Pesquisador do Centro de Investigação Media e Jornalismo
\end{abstract}

\begin{abstract}
Resumo
A ditadura em Portugal (1926-1974) foi a mais longa de toda a Europa Ocidental no século XX. O período de 48 anos de regime autoritário foi determinante para o atraso na institucionalização do ensino do jornalismo no país, que culminou com a criação da primeira Licenciatura em Comunicação Social, em 1979. O artigo irá abordar o tema "ensino do jornalismo" em Portugal, sob uma perspectiva histórica e irá descrever, de forma sucinta, as principais iniciativas em prol da criação de cursos e instituições, que contribuíram ou poderiam ter colaborado para a institucionalização do ensino do jornalismo. O artigo descreverá, a partir da reorganização do panorama das Ciências Sociais em Portugal, como foi possível a criação da primeira Licenciatura em Comunicação Social, na Faculdade de Ciências Sociais e Humanas (FCSH), na Universidade Nova de Lisboa (UNL), em 1979. Os princípios que orientaram a criação da licenciatura serão expostos.
\end{abstract}

\section{Palavras-chave}

Ensino; comunicação social; jornalismo.

\begin{abstract}
The dictatorship in Portugal (1926-1974) was the longest of all of Western Europe in the twentieth century. The period of 48 years of authoritarian rule was crucial to the delay in the institutionalization of journalism education in the country, culminating with the creation of the first degree in Social Communication in 1979. The article will address the topic "journalism education" in Portugal, from a historical perspective and will describe, briefly, the main initiatives for the establishment of courses and institutions that contributed or could have contributed to the institutionalization of journalism education. The article will describe, from the reorganization of the landscape of Social Sciences in Portugal, as it was possible the creation of the first degree in Social Communication at the Faculty of Social Sciences and Humanities, New University of Lisbon, in 1979. The principles that guided the creation of the degree will be exposed.
\end{abstract}

\section{Keywords}

Education; social communication; journalism 


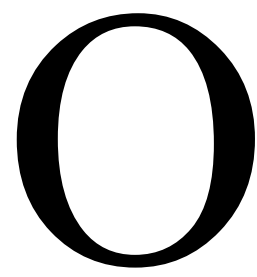

longo período de ditadura em Portugal foi determinante para o atraso na institucionalização do ensino do jornalismo no país. Em 1958, a UNESCO publicou os resultados de um estudo que indica a existência de 650 estabelecimentos de ensino do jornalismo espalhados pelo mundo ( $80 \%$ tinham "caráter universitário", e os restantes $20 \%$ "caráter prático"), notando que "Portugal é um dos raros países onde não existe uma Escola de Jornalismo" (UNESCO apud CASCAIS, 2003, p. 68). Em 1970, somente 1\% dos jornalistas portugueses possuíam diplomas universitários em Portugal, segundo Cascais (2003, p. 70), enquanto nos Estados Unidos existiam 36.697 alunos inscritos em Licenciaturas de jornalismo, em 1971, de acordo com Traquina (2002, p. 68).

As características intrínsecas do regime autoritário português determinaram o cenário de profundo atraso para o ensino do jornalismo, uma vez que Salazari ${ }^{\mathrm{ii}}$ olhava para a imprensa como uma força de oposição ao Estado Novoiii. Na vizinha Espanha, comandada pelo ditador Francisco Franco, existiam escolas de jornalismo sob controle do Ministério de Informação e Turismo, que instrumentalizou o jornalismo em favor da sua ideologia autoritária. Segundo Canel M. J. (apud WEAVER, 1998, p. 305), o ensino universitário do jornalismo na Espanha foi estabelecido a partir de 1972. Com um avanço de mais de um século em relação a diversos países europeus, os pioneiros no estabelecimento do ensino universitário do jornalismo foram os Estados Unidos, na década de 1860. Traquina (2002, p. 67) refere as instituições que contribuíram para o estabelecimento da instrução jornalística formal: Universidade de Washington, que possuía outro nome à época; Kansas State College, em 1873; Universidade do Missouri, em 1878; e Universidade da Pensilvânia, em 1893. Traquina (2002, pp. 67, 69) escreve que na França o mesmo tipo de ensino surgiu em 1899 através de um norte-americano, Dick May, fundador da Escola Superior de Jornalismo, baseando-se no modelo da Universidade de Pensilvânia.

A revisão das principais ações em prol da criação de cursos e instituições de ensino do jornalismo, no período de 1941 a 1979, em Portugal, evidenciou uma necessidade histórica, que uma parte da classe jornalística possuía em alcançar um maior grau de profissionalização, através da formação profissional e do ensino sistematizado do jornalismo. Esta necessidade de aperfeiçoamento profissional era confrontada com uma ideologia fechada em si mesma e centrada na crença de que o jornalismo se aprendia na tarimba ${ }^{\mathrm{iv}}$, através da prática exercida nas redações dos jornais 
Estudos em Jornalismo e Mídia - Vol. 9 № 2 - Julho a Dezembro de 2012

e não através de formação específica, sistematizada e estruturada. Contudo, já na década de 1970 se observava uma tendência para a alteração desta perspectiva, que não era compartilhada por todos os profissionais.

No léxico jornalístico português, a palavra tarimbeirov ${ }^{v}$ foi uma designação comumente utilizada no passado, aplicada a um determinado tipo de jornalista, que tornava-se profissional através das técnicas que experienciava nas redações e através dos constrangimentos organizacionais, como descreve a "Teoria organizacional", de Warren Breed, segundo a qual o aprendizado das regras e normas do trabalho jornalístico é baseado "num processo de socialização organizacional em que é sublinhada a importância de uma cultura organizacional, e não de uma cultura profissional" (TRAQUINA, 2002, p. 80). A palavra tarimbeiro é utilizada para descrever os jornalistas que surgiram durante o Salazarismo ${ }^{\mathrm{vi}}$, com acesso restrito, quase inexistente, à formação profissional e ao ensino do jornalismo.

Alguns cursos rápidos de jornalismo em Portugal foram concretizados e beneficiaram uma parcela de jornalistas. Outros projetos que contribuiriam para a institucionalização do ensino no país não foram concluídos. Apesar de pontuais, todas as iniciativas contribuíram para o debate e reflexão sobre o ensino do jornalismo, interferindo na criação da primeira Licenciatura em Comunicação Social em 1979.

\section{O fracasso da primeira tentativa de um Curso de Formação Jornalística (1941)}

Foi em 08 de Fevereiro de 1941 que o presidente da Comissão Administrativa do Sindicato Nacional dos Jornalistas (SNJ) ${ }^{\text {vii }}$, Luís Teixeira, entregou no Departamento de Estado da Educação Nacional, o texto do projeto do Curso de Formação Jornalística, que tinha como objetivo a "valorização profissional dos jornalistas e o elevar o seu nível cultural até aos limites exigidos pela missão que desempenham na vida portuguesa" (SOBREIRA in TRAQUINA, (org.) 2010, p. 5). À época a vocação e o autodidatismo eram as credenciais necessárias para os profissionais iniciarem na profissão.

O desenvolvimento profissional acontecia nas redações dos jornais, sem qualquer formação estruturada. Segundo Correia e Baptista (2007, p. 408), o curso proposto aconteceria em dois anos, constituído por disciplinas teóricas, conferências livres e exercícios práticos, estando igualmente previstas visitas de estudo às redações e às gráficas mais importantes. Para entrar no curso o candidato deveria ter o $5^{\circ}$ ano do liceu 
Estudos em Jornalismo e Mídia - Vol. 9 № 2 - Julho a Dezembro de 2012

(equivalente ao ensino médio no Brasil), ou comprovar o mínimo de um ano de exercício da profissão, e ser português.

Uma equipe constituída pelos principais profissionais e acadêmicos foi convidada a lecionar. $\mathrm{O}$ curso propunha um espectro de formação alargado, passando por cultura geral, aspectos técnicos e reflexivos específicos do jornalismo e uma componente ligada à elaboração dos jornais. Esta primeira tentativa foi frustrada, já que o SNJ não conseguiu reunir os recursos necessários para a realização do curso, não tendo o Estado apoiado a iniciativa.

\section{O Curso de Iniciação Jornalística do Diário Popular (1966)}

Foi necessário um intervalo de 26 anos para que uma segunda tentativa de realização de um curso de jornalismo fosse bem-sucedida. Sem qualquer ligação direta ao poder político, escrevem Correia e Baptista (2007, p. 414), a iniciativa da criação do Curso de Iniciação Jornalística, entre Abril e Maio de 1966, foi realizada pelo Diário Popular (DP) ${ }^{\text {viii }}$. A iniciativa foi a primeira ligada ao ensino do jornalismo a ser realizada em Portugal. O curso tinha como objetivo central recrutar jornalistas para trabalharem no próprio jornal. As razões que determinaram a criação deste curso foram a dificuldade em encontrar jornalistas profissionais que correspondessem às exigências do DP e o risco derivado da admissão de jovens sem qualquer experiência. $\mathrm{O}$ curso foi a reposta encontrada para a necessidade de renovação da redação do jornal, através do seu rejuvenescimento.

Francisco Pinto Balsemão ${ }^{\text {ix }}$ foi o idealizador e o promotor do curso, que ensinava e avaliava os candidatos, identificando os melhores, com o objetivo de integrá-los na redação do jornal. Com um máximo de 25 alunos, e uma duração de 20 dias (das 20 às 24h), a primeira parte do curso abordava temas gerais relacionados com a imprensa, e na segunda parte estudava-se o DP, a sua história e objetivos. Os candidatos deveriam ter menos de 30 anos, ter concluído o $7^{\circ}$ ano de liceu, e poder assistir a todas as aulas, comprometendo-se a prestar todas as provas e querer trabalhar na redação do jornal. Condições como: falar e escrever uma ou mais línguas estrangeiras; ter o serviço militar cumprido; ter curso universitário ou já ter tido alguma experiência como jornalista; além de saber datilografar com rapidez, eram preferenciais. Os profissionais do jornal eram também os professores do curso, segundo Correia e Baptista (2007, p. 414). 
Estudos em Jornalismo e Mídia - Vol. 9 № 2 - Julho a Dezembro de 2012

A avaliação final consistia em dois dias de provas escritas e dois dias de provas orais. À época, a necessidade de profissionais mais qualificados, a maior qualidade exigida pelos leitores e a introdução de novas ferramentas de trabalho ou novas tecnologias, como a máquina de escrever "de que os jornalistas do DP dispunham desde o início da década mas que noutros importantes diários só anos mais tarde se generalizaria" (CORREIA e BAPTISTA, 2007, p. 414), foram elementos que pressionaram os avanços do jornalismo português.

\section{O êxito do I Curso de Jornalismo do Sindicato Nacional dos Jornalistas (1968)}

A segunda iniciativa bem-sucedida de um curso de jornalismo aconteceu com o I Curso de Jornalismo organizado pelo Sindicato Nacional dos Jornalista (SNJ), com apoio do Estado. O curso teve início em 21 de Novembro de 1968, no Sindicato dos Caixeiros, com a duração de 4 meses. Foi celebrado, tanto pelo SNJ, quanto pelo governo. A ideia de lançar o curso nasceu dentro do próprio Sindicato, bem como a possibilidade da criação de uma Escola de Jornalismo, como resultados de quatro debates que aconteceram entre 12 de Junho e 24 de Julho de 1967, em torno do tema "situação do jornalista profissional português" (SJ, 1968).

A partir dos debates foram identificadas as principais dificuldades da classe: "salários irrisórios, que obriga a maioria a procurar fora da profissão o complemento necessário para se manter dignamente; burocratização da informação que deu como resultado a burocratização do noticiário, tornando-se geral o recurso ao corte e cola; falta de cultura de base e de especialização" (SJ, 1968). Uma comissão foi formada no sentido de concretizar o I Curso de Jornalismo, que seria voltado tanto quanto possível aos profissionais, pois destinava-se ao aperfeiçoamento e formação profissional dos sócios do Sindicato.

O curso foi considerado um sucesso pela maior parte dos jornais da época. Foi criada uma modalidade de ensino do curso por correspondência, face à grande procura, como salientou o jornalista e presidente do Sindicato, Pereira da Costa, no seu discurso na sessão de encerramento do curso:

Os participantes no curso, entre alunos por frequência e por correspondência, totalizaram 385 interessados, incluindo 187 profissionais. Deste total, 207 acompanharam o curso por correspondência, cerca de uma centena da Metrópole, 84 de Angola, 
28 de Moçambique, um de Macau e dois portugueses residentes em Itália (DIÁRIO DE NOTÍCIAS, sem autor, 1969).

Neste mesmo discurso, Pereira da Costa informou que a quase totalidade dos participantes particulares (não profissionais) eram estudantes universitários, um argumento que sustentava a necessidade de se constituir uma escola de jornalismo:

Quanto a estes [estudantes universitários] é sintomática, sem dúvida, a circunstância de, ao cabo de quatro meses de realização do curso, ainda assistirem às aulas na proporção de oitenta e sete por cento sobre os que inicialmente nele se tinham inscrito, manifestando entusiasmo que nos provocou como que um complexo de inferioridade.

O presidente do Sindicato reconheceu que o curso ficou aquém das expectativas dos alunos. Mesmo que o curso tenha sido criado para atender às necessidades de formação dos profissionais, uma das dificuldades que enfrentaram os professores era derivada da heterogeneidade da audiência, já que além de jornalistas, também eram alunos:

\footnotetext{
bancários, uma hospedeira [aeromoça] da TAP, um comissário de bordo, funcionários públicos, empregados de escritório, estudantes universitários, tradutores, oficiais milicianos, um padre, advogados, um controlador de tráfego aéreo, um meteorologista, um profissional de hotelaria, engenheiros, bibliotecários (CORREIA e BAPTISTA, 2007, p. 419).
}

A diversidade dos participantes gerou críticas ao curso; em decorrência, foram aventadas soluções, como a criação de cursos de jornalismo específicos para jornalistas, e não jornalistas.

Personalidades públicas que faziam parte do regime participaram em grande número na sessão de encerramento do curso. As notícias e reportagens realizadas a propósito do encerramento do curso evidenciaram um conteúdo homogeneizado, por vezes meras reproduções dos discursos oficiais, como por exemplo, a publicada no jornal Diário de Notícias (DIÁRIO DE NOTÍCIAS, sem autor, 1969), marcada pela convergência dos discursos. Fortemente influenciado pelo poder do Estado, o presidente do SNJ, em sua intervenção no encerramento do curso, afirma que "o curso constituiu um êxito insofismável”.

\section{O projeto de Ensino de Jornalismo em Portugal do SNJ (1970)}

O Projeto de Ensino de Jornalismo em Portugal, do SNJ, inspirou-se no modelo universitário de ensino das Ciências Sociais e Humanas, com referências de sistemas de 
Estudos em Jornalismo e Mídia - Vol. 9 № 2 - Julho a Dezembro de 2012

ensino da Alemanha, Bélgica, França, Itália e Holanda. A razão desta característica deve-se ao fato de três conselheiros técnicos que participaram na comissão do projeto terem feito suas licenciaturas em jornalismo, em outros países, segundo Correia e Baptista (2007, p. 419): José Lechner (Escola de Jornalismo de Lile), Oliveira Figueiredo (Escola de Jornalismo da Igreja, de Madrid), e Carlos Ponte Leça (Escola de Jornalismo da Universidade de Navarra). Após as experiências de 1941 e 1968, o projeto em questão atingiu um elevado grau de maturidade. O documento, com 19 páginas, informa que Portugal era dos raros países onde não existia uma escola de jornalismo e destaca a necessidade de formação específica para os jornalistas.

A proposta do projeto de 1970 foi aprovada em assembleia geral do Sindicato em 10 de Dezembro do mesmo ano, e submetia o ensino a conteúdos acadêmicos, além de propor uma designação mais geral de "Ciências da Informação". A necessidade de uma componente científica na formação é clara no projeto. A importância das matérias humanísticas também surge como solução para uma compreensão mais ampla sobre o conjunto das problemáticas contemporâneas. O projeto de ensino deveria ser aplicado de forma sistemática e previa a criação do "Instituto Superior de Ciências da Informação', com o objetivo de formar bacharéis e licenciados em 'Ciências da Informação', aptos a exercer 'jornalismo', 'radiojornalismo', 'telejornalismo' e 'cinejornalismo"” (SOBREIRA, 2003, p. 179). O curso seria composto por três grandes eixos: Ciências da Informação, Técnica da Informação e Cultura para Informação.

Para os três primeiros anos estavam programadas disciplinas de âmbitos gerais e para as disciplinas de especialização existiria um conteúdo curricular com diversas disciplinas jornalísticas. A criação do Instituto Superior da Ciência da Informação, aventada pelo projeto, formaria bacharéis, licenciados e doutores. Para que os profissionais com mais de 25 anos de idade tivessem acesso ao curso, seria exigido um mínimo de 5 anos de exercício da profissão. O projeto do SNJ representava o acesso dos futuros profissionais a formação acadêmica universitária, e se fosse concretizado constituiria um marco na história do ensino e do jornalismo portugueses.

O projeto foi rejeitado por diversos políticos e até por jornalistas. Era a posição de uma parte dos jornalistas sobre o projeto:

Não será isto denunciador da ideologia desta proposta e dos fins que objetivamente serve - a constituição de uma espécie de feudo ou mandarinato da informação a que só os "doutores", os "bacharéis" ou os "licenciados" terão direito de acesso? Nós os jornalistas "especializados" que sabemos, não somos os professores da opinião pública, temos o segredo da informação - os outros só têm de ouvir caladinhos as nossas verdades universitárias (REIS, 1973). 
O presidente do SNJ exerceu certa pressão em seu discurso aquando da entrega do projeto ao Ministro da Educação Nacional, Veiga Simão: “Terá chegado a vez de Portugal possuir ensino do jornalismo a nível universitário? Correu o mundo a falsa ideia de que o jornalista nasce, não se faz. Os jornalistas portugueses, pelo contrário, negam-se a confiar em métodos empíricos a formação dos futuros profissionais" (SNJ, 1971).

Os membros do Sindicato estavam determinados em executar o projeto que, se concretizado, valorizaria a profissão de forma efetiva. O SNJ tentou pressionar o ministro Veiga Simão:

Não tendo entrado ainda em funções o grupo de trabalho cuja formação foi superiormente prevista por Vossa Excelência, a direção do Sindicato apenas tem conhecimento, obtido pelo primeiro dos signatários em conversa pessoal com Sua Excelência o senhor Presidente do Concelho, de que está nas mãos de Vossa Excelência a promoção do ensino do jornalismo - cometida do governo a Base XII de Lei de Imprensa (SNJ, 1972).

Uma vez mais, uma iniciativa que contribuiria para a emancipação da classe jornalística fracassou, por omissão dos agentes da ditadura.

\section{A Escola Superior de Meios de Comunicação Social (1971)}

Após aprovação do Ministério Nacional da Educação, a Escola Superior de Meios de Comunicação Social (ESMCS), criada em 1971 foi aberta no Instituto de Línguas e Administração, a "primeira instituição portuguesa de ensino superior particular, fundada em 1962" (CORREIA e BAPTISTA, 2007, p. 428). Com os cursos de Jornalismo, Relações Públicas, Publicidade, Rádio e Televisão, os estudos durariam três anos. A criação da escola foi aceita pelo poder político vigente e tinha patrocinadores que garantiam condições jurídicas e financeiras para a sua existência. $\mathrm{O}$ banco Borges \& Irmão, um dos maiores em Portugal, cujo diretor principal possuía dois jornais, o Diário Popular e o Jornal do Comércio, além de uma agência de publicidade, Latina, convergiram esforços e pessoas no sentido de tornar o projeto um êxito. Ao mesmo tempo que o capital derivado do setor bancário para a constituição da ESMCS foi fundamental para a sua criação, também foi a razão da extinção da escola, pois após o 25 de Abril de $1974^{x}$ o setor bancário foi nacionalizado (ibidem, p. 429). Mesmo assim a escola sobreviveu alguns anos tendo sido fechada na década de 1980. 


\section{Análise breve sobre o fracasso das iniciativas ligadas ao ensino do jornalismo}

As iniciativas de 1941 e 1970 conduzidas pelo SNJ possuem em comum a omissão do Estado, a principal razão por não se terem concretizado. Silva Costa, presidente do SNJ em 1970, dizia que "havia gente demais interessada na tutela do ensino do jornalismo", referindo-se aos conflitos entre o Ministério da Educação, o Ministério das Corporações e a Secretaria de Estado da Informação - representando a própria Presidência do Concelho. A educação e a Comunicação Social, no Estado Novo, eram elementos que não se ajustavam, eram campos antagônicos. Neste contexto, o ensino do jornalismo operava como hipótese libertadora para a classe jornalística, que atuava no campo de uma Comunicação Social domesticada e cerceada, segundo os propósitos do regime.

Com o início do Marcelismo ${ }^{\mathrm{xi}}$, um período de avanço é alcançado no campo do jornalismo, em razão da criação da primeira escola de jornalismo ESMCS, do projeto de Lei de Imprensa apresentado por Francisco Sá Carneiro ${ }^{\text {xii }}$ e Francisco Pinto Balsemão e da fundação do semanário Expresso (CASCAIS, 2008, p. 11). Quanto à criação da ESMCS, esta escola teve existência efêmera porque estava subjugada aos interesses do capital, desta vez apoiada pelo governo. Os interesses do governo mantiveram a escola ativa, já que estavam a ser influenciados por um relatório da OCDE, que indicava a necessidade da formação de quadros técnicos, em resposta às necessidades econômicas e sociais vigentes (CASCAIS, 2003, p. 62).

Soma-se a esta interferência, o fato de a escola não precisar de capital estatal para funcionar. Mais uma vez os interesses da classe jornalística foram subjugados aos interesses do governo, que encontrava nesta escola de jornalismo uma solução para a introdução dos institutos politécnicos em Portugal, como parte de uma estratégia de crescimento nacional. Com a nacionalização dos bancos na sequência do 25 de Abril a existência da ESMCS tornou-se inviável, entretanto a escola resistiu até a década de 80 .

Se por um lado os agentes externos envolvidos nas sucessivas tentativas de institucionalizar o ensino do jornalismo em Portugal tiveram diferentes graus de responsabilidade pelo fracasso destas mesmas iniciativas, por outro, os próprios jornalistas também foram responsáveis. A apatia intelectual que abatia sobre os jornalistas, a respeito do modelo mais adequado para o ensino do jornalismo, condicionou as formas de pensar a profissão durante os duros períodos da ditadura, com reflexos nas décadas que sucederam. A lenta velocidade com que o processo de 
Estudos em Jornalismo e Mídia - Vol. 9 № 2 - Julho a Dezembro de 2012

institucionalização do ensino do jornalismo se deu, a partir do fim da década de 1970, foi determinada pelo condicionamento das mentalidades dos jornalistas, em torno da cristalização do dogma de que o jornalismo se aprende na prática. A universidade e a profissão eram elementos com pouca ligação para as mentalidades da época. A discussão era centrada na dicotomia entre teoria e prática, uma discussão que persiste até à atualidade.

Segundo Weaver, o reconhecimento da liberdade e da autonomia por parte dos jornalistas, está relacionado, em muitos casos, com o nível de satisfação profissional, um importante indicador das condições de trabalho (WEAVER, 1998, p. 461). Os jornalistas foram vítimas da sua própria condição até ao 25 de Abril. Com a liberdade cerceada e sem autonomia, as condições de trabalho permaneceram deterioradas, logo, o ambiente profissional não era propício para que novas perspectivas fossem alcançadas. Sem uma convergência ideológica, não existia consenso ao redor de temas determinantes para o aprimoramento da profissão, como o ensino do jornalismo.

\section{Da precariedade à reorganização das Ciências Sociais em Portugal}

Foi a partir da reorganização das Ciências Sociais em Portugal que foram criadas as condições para a criação da primeira licenciatura em Comunicação Social, em 1979, na Faculdade de Ciências Sociais e Humanas (FCSH), na Universidade Nova de Lisboa (UNL). O panorama das Ciências Sociais em Portugal, antes de 1979, era limitado e marginal no quadro das universidades portuguesas. Para uma maior compreensão das razões e do contexto da criação da primeira Licenciatura em Comunicação Social em Portugal, se faz necessário um enquadramento relativo à situação desta área do saber no país. Segundo o professor Adriano Duarte Rodrigues ${ }^{x i i i}$ (RODRIGUES, 2010a), fundador do Departamento de Comunicação Social da FSCH, havia poucos cursos na área das Ciências Sociais: um Curso de Sociologia no Instituto Superior da Ciência do Trabalho e da Empresa (ISCTE); um Curso de Estudos Ultramarinos, com forte componente antropológica, ministrado no Instituto Superior de Ciências Sociais e Políticas Ultramarinas (ISCSPU); iniciativas conduzidas em Coimbra em torno da Faculdade de Economia, através do professor Boaventura de Sousa Santos; e um Curso de Sociologia que havia sido criado na UNL, mas que não funcionava por entraves internos da Universidade (RODRIGUES, 2010a). 
Estudos em Jornalismo e Mídia - Vol. 9 № 2 - Julho a Dezembro de 2012

Foi a partir deste quadro de precariedade da área das Ciências Sociais que Adérito Sedas Nunes ${ }^{\text {xiv }}$, antes de se tornar Ministro da Coordenação Cultural, Cultura e Ciência, do V Governo Constitucional, liderado por Maria de Lourdes Pintassilgo ${ }^{\mathrm{xv}}$, redige um memorando (NUNES, 1979) sobre a criação de um "Instituto de Investigação e Pósgraduação em Ciências Sociais", que é também um diagnóstico do estado pedagógico e científico da área em questão. Na primeira linha do documento, de Maio de 1979, lê-se: "A situação das Ciências Sociais em Portugal encontra-se, neste momento, num ponto crítico." Baseado neste memorando, poucos meses depois, algumas soluções para os problemas identificados se convertem em propostas políticas no "Programa do V Governo Constitucional" (PCM, s.d.). No que toca à área científica e cultural, o documento afirma que o Governo procurará desenvolver uma infra-estrutura para atender aos objetivos de uma política científica e tecnológica, por intermédio das instituições existentes; a nível do ensino superior, foi determinado o desenvolvimento de novas universidades e institutos universitários.

Adriano Rodrigues, que à época ocupava o cargo de Assessor da Secretaria de Estado do Ensino Superior, foi convidado por Sedas Nunes a participar de uma comissão encarregada da organização dos cursos de Ciências Sociais nas universidades portuguesas, com um prazo reduzido para a conclusão do projeto (RODRIGUES, 2010a). O objetivo central da comissão era a distribuição regional da oferta curricular e a diferenciação das especializações em Ciências Sociais. Na sua opinião, a comissão não conseguiu o ideal, mas atingiu o equilíbrio na regulação da oferta curricular. $O$ conhecimento mais amplo das Ciências Sociais, sob uma perspectiva internacional, era a marca da comissão, segundo o professor:

Todos nós tínhamos uma formação acadêmica, a maior parte estrangeira. Muitos vinham dos Estado Unidos, da Alemanha, da França, da Inglaterra. Nós tínhamos, embora com culturas diferentes, uma formação sólida no quadro epistemológico das Ciências Sociais, sabíamos o que queríamos, sabíamos o que fazia falta para nos enquadrarmos no contexto internacional e depois tínhamos acesso a muita informação que recolhíamos de outros cursos (RODRIGUES, 2010a).

Apesar de rápida, a atuação da comissão foi intensa. A distribuição das especializações das Ciências Sociais foi realizada, e de forma concomitante a abertura das universidades portuguesas ao mundo acadêmico internacional. A consolidação do projeto levou muitos anos, ajustes foram feitos, e sob a perspectiva avaliativa de Adriano Rodrigues, "houve equipes que se formaram mais dinâmicas e que conseguiram implantar-se melhor, a nível nacional, ou internacional; criaram-se 
Estudos em Jornalismo e Mídia - Vol. 9 № 2 - Julho a Dezembro de 2012

revistas, houve equipes que se alargaram, especialidades que se desdobraram, depois, é a história, já lá vão 30 e tal anos". O trabalho da comissão resultou num relatório, que daria origem a um decreto promulgado pelo general Ramalho Eanes ${ }^{\mathrm{xvi}}$, no qual era definido a oferta dos cursos em Ciências Sociais, nas diferentes universidades portuguesas, segundo Portaria $n^{\circ}$. 663/79 de 10 de Dezembro do Ministério da Educação.

\section{Os princípios que orientaram a criação da Licenciatura em Comunicação Social}

Neste cenário de profundas transformações das Ciências Sociais, a FCSH foi incumbida da reformulação dos cursos de Sociologia e de Antropologia, que já existiam, segundo Adriano Rodrigues, mas foram reorganizados em razão de um novo enquadramento, derivado dos cursos das outras universidades do país, em particular da região de Lisboa. A UNL vivia um clima de instabilidade com lutas entre os professores, que não se entendiam. As lutas a que Adriano Rodrigues se refere aconteciam entre professores especializados numa determinada área, mas que lideravam cursos de outra área. Foram criados cursos para colmatar lacunas. Houve negociações com o presidente da Comissão Instaladora, o historiador Oliveira Marques e, como consequência, uma distribuição coerente dos cursos.

A comissão nomeada por Sedas Nunes reconheceu que a Licenciatura em Comunicação Social deveria permanecer sob a coordenação do professor Adriano Rodrigues, na UNL, doutor em Ciências da Comunicação, como esclarece, "A distribuição de cursos teve em conta a localização geográfica, mas também onde havia pessoas aptas. Não havia mais ninguém doutorado em Comunicação no país, eu era o único" (RODRIGUES, 2010a). Segundo o professor a negociação para a criação da Licenciatura em Comunicação Social foi extremamente fácil, porque ainda não existiam órgãos de gestão, a questão era tratada com o presidente da Comissão Instaladora ${ }^{\text {xvii }}$.

Através do Decreto $\mathrm{n}^{\circ}$. 128-A/79, de 23 de Novembro, publicado no Diário da República, o Ministério da Educação "cria na Faculdade de Ciências Sociais e Humanas da Universidade Nova de Lisboa o curso de Licenciatura em Comunicação Social.” Em menos de um mês, os planos de estudos dos cursos de Ciências Sociais abertos na UNL, na Universidade do Minho, no Instituto Universitário de Évora e no Instituto Superior de Ciências do Trabalho e da Empresa, são divulgados na Portaria ${ }^{\circ}$. 663/79, de 10 de 
Estudos em Jornalismo e Mídia - Vol. 9 № 2 - Julho a Dezembro de 2012

Dezembro. Durante os três primeiros anos, a Licenciatura em Comunicação Social foi, juntamente com as de Antropologia e Sociologia, uma das variantes do curso de Ciências Sociais.

Adriano Rodrigues sintetiza as linhas que orientaram a criação da Licenciatura da seguinte forma:

O paradigma comunicacional que serviu desde o começo do Departamento, como orientação para os seus projetos de formação e para a definição de suas temáticas de investigação, decorre da tomada de consciência da natureza constitutiva daquilo a que damos o nome de lógica da relação, como constituição da experiência, sendo a experiência para a espécie humana o fundamento de toda a possibilidade de conhecimento e de ação (RODRIGUES, 2010c).

O centro reflexivo da Licenciatura incidia sobre a releitura de textos de Immanuel Kant, Friedrich Hegel e dos diferentes legados fenomenológicos, dos grandes pensadores da experiência moderna. Adriano Rodrigues sublinha duas teorias que marcaram a Licenciatura: teorias da informação e teoria dos sistemas.

Suas inspirações para o desenvolvimento dos eixos orientadores da área de Ciências Sociais da UNL foram uma matriz sociológica preocupada com a criação das sociabilidades do mundo moderno, no mundo urbano, e toda a matriz lógica e psicológica, voltada para a vertente comportamental. Todas estas referências filtradas por uma abordagem em torno da linguagem. As diretrizes administrativas e estruturais do Departamento são descritas num documento dirigido ao presidente da Comissão Instaladora da FCSH, em 19 de Maio de 1981 (RODRIGUES, 1981), elaborado pelo próprio coordenador Adriano Rodrigues. $\mathrm{Na} F C S H$, inicialmente, o primeiro ano das Licenciaturas em Sociologia, Antropologia e Comunicação Social, possuía um tronco comum: a maior parte das disciplinas eram as mesmas para os cursos, bem como os professores.

Em um relatório de 1980 do Ministro da Coordenação Cultural e da Cultura e Ciência, é descrita a linha de ação do Departamento de Comunicação Social, para o ano de 1981. Este relatório também informa o número de professores do Departamento, no total 15: um professor catedrático, três assistentes convidados, oito assistentes e três professores secundários. O relatório de 1980 descreve os objetivos prioritários do Departamento de Comunicação Social para o próximo ano letivo, um deles relacionado com o desenvolvimento da equipe e o outro ligado às demandas do sector da Comunicação Social (RODRIGUES, 1980). 
Estudos em Jornalismo e Mídia - Vol. 9 № 2 - Julho a Dezembro de 2012

A Bélgica e a França eram os países onde se iam contratar professores. Segundo Adriano Rodrigues, nos dias atuais só existem professores da segunda geração de alunos na FCSH:

Uma das pessoas que viveu bastante este espírito, mas que era aluno nessa época, é o João Pissarra, e a Teresa Cruz, ambos foram alunos da Licenciatura e hoje dão aulas aqui. [...] Depois, mais tarde, vem então o Nelson Traquina, que entra numa fase em que o Departamento se abriu um pouco à formação jornalística, foi uma coisa muito tardia (RODRIGUES, 2010a).

Para a história do Departamento de Comunicação Social, o final da década de 1980 representou um momento decisivo para a formação do que é hoje o Departamento de Ciências da Comunicação da FCSH-UNL:

a década de 80 é um período importante de abertura, de criação de um maior número de disciplinas, recrutamento de novos professores, o início dos estudos de pós-graduação. O elemento mais importante para mim é o corpo docente ter ganhado em diversidade, aí sim se faz a configuração do curso muito próxima daquilo que ele é hoje. $\mathrm{O}$ período crucial é entre o final dos anos 80 e os anos 90, quando o curso muda de nome (ESTEVES, 2011).

\section{Considerações finais}

Consideramos relevante ressaltar o papel da investigação histórica do jornalismo. Este tipo de investigação "contextualiza os pequenos e os grandes problemas, combinam eventos, temas, personalidades através do tempo, e os convertem em narrativa, que visa restituir o passado do jornalismo como um fenômeno com mais pontos preenchidos do que lacunas" (GOLDING \& ELLIOTT 1979 apud ZELIZER, 2004, p. 81).

O pioneirismo da Licenciatura em Comunicação Social eleva a importância do curso enquanto nova área de estudos no campo das Ciências Sociais, beneficiada com o início de uma profunda transformação, conduzida à época por Adérito Sedas Nunes, Ministro da Coordenação Cultural, Cultura e Ciência, do V Governo Constitucional, que transformaria por completo o panorama nacional desta grande área do saber. Sob a perspectiva dos jornalistas da época, a criação da Licenciatura em Comunicação Social fez com que a questão do ensino do jornalismo regressasse a agenda da classe, após o longo histórico de tentativas mal sucedidas para instituição do ensino do jornalismo, como forma de aprimoramento profissional, mas principalmente, como meio para atingir uma maior valorização profissional, com concomitante reconhecimento social. 


\section{Referências bibliográficas}

A profissão de jornalista enaltecida pelo Dr. César Moreira Batista, na sessão de encerramento do $1^{\circ}$ Curso de Jornalismo. Jornal Diário de Notícias, Lisboa, 15 mai. 1969.

A situação do jornalista profissional português. Jornalismo, Lisboa, nº 7, out. 1968.

CANEL, María José; PIQUÉ, Antoni M. Journalists in Emerging Democracies: The Case of Spain. In WEAVER, David H. The global journalist, news people around the word. New Jersey: Hampton Press, 1998.

CASCAIS, Fernando Ensino do jornalismo em Portugal. História de um fracasso dos jornalistas. Revista do Centro de Investigação Media e Jornalismo. No 13, Ano 8 Outono/Inverno 2008. Lisboa, 2008.

CASCAIS, Fernando O Exercício do Jornalismo em Portugal - Ensino do Jornalismo - Contributo para a sua história (1968-1974). Lisboa: Programa de Doutoramento em Comunicação Social, Universidade Complutense de Madrid - Instituto Politécnico de Lisboa/Escola Superior de Comunicação Social, 2003.

CORREIA, Fernando; BAPTISTA, Carla Jornalistas do ofício à profissão, mudanças no jornalismo português (1956-1968). Lisboa: Editora Caminho, 2007.

ESTEVES, João Pissarra. João Pissarra Esteves: depoimento [fev. 2011]. Entrevistador: R. R. Mendes. Lisboa: FCSH-UNL, 2011. áudio mp3 85 minutos. Entrevista concedida no âmbito da tese de mestrado com o título A Primeira Licenciatura em Comunicação Social em Portugal (FCSH-UNL, 1979) contributo para uma reflexão acerca do ensino do jornalismo

JORNALISTAS, Sindicato Nacional. Carta da direcção do Sindicato Nacional dos Jornalistas ao Ministro da Educação Nacional. Lisboa: SNJ, 1972

JORNALISTAS, Sindicato Nacional. Discurso proferido por Silva Costa, presidente do Sindicato Nacional dos Jornalistas. Lisboa: SNJ, 1971

NUNES, Adérito Sedas. Memorando sobre a criação de um Instituto de Investigação e Pós-graduação em Ciências Sociais Memorando. Lisboa: 1979

Programa do V Governo Constitucional. Programa do V Governo Constitucional. Lisboa. s.d.

REIS, Miguel. Jornalismo uma iniciativa vital? CF, 1973

RODRIGUES, A. A primeira licenciatura em Ciências da Comunicação. In: SEMINÁRIO SOBRE O ENSINO DO JORNALISMO E IDENTIDADE PROFISSIONAL, 4, 2010c, Lisboa: UNL, 2010.

RODRIGUES, Adriano Duarte. Carta de Adriano Rodrigues ao presidente da Comissão Instaladora da FCSH da UNL. Lisboa: UNL, 1982

RODRIGUES, Adriano Duarte. Linhas de acção da Comunicação Social para o ano de 1981. Lisboa: UNL, s.d.

RODRIGUES, Adriano. Adriano Duarte Rodrigues: depoimento [jun. 2010]. Entrevistador: R. R. Mendes. Lisboa: FCSH-UNL, 2010. áudio mp3 96 minutos. Entrevista concedida no âmbito da tese de mestrado com o título A Primeira Licenciatura em Comunicação Social em Portugal (FCSH-UNL, 1979) - contributo para uma reflexão acerca do ensino do jornalismo

SOBREIRA, Rosa Maria O Ensino do Jornalismo e a Profissionalização dos Jornalistas em Portugal (1933-1974) in TRAQUINA, Nelson (org.) Do Chumbo à era Digital. Lisboa: Livros Horizonte, 2010.

SOBREIRA, Rosa Maria Os jornalistas portugueses 1933 - 1974, uma profissão em construção. Lisboa: Livros Horizonte, 2003.

TRAQUINA, Nelson O que é jornalismo. Lisboa: Quimera, 2002.

UNESCO The Training of journalists. 1958 In CASCAIS, Fernando O Exercício do Jornalismo em Portugal - Ensino do Jornalismo - Contributo para a sua história (1968-1974). Lisboa: Programa de Doutoramento em Comunicação Social, Universidade Complutense de Madrid - Instituto Politécnico de Lisboa/Escola Superior de Comunicação Social, 2003.

WEAVER, David H. The global journalist, news people around the word. New Jersey:: Hampton Press, 1998.

ZELIZER, Barbie Taking journalism seriously. United States of America: Sage Publications, 2004. 
Este artigo foi produzido como resultado da tese de mestrado, defendida em 2011, com o título "A Primeira Licenciatura em Comunicação Social em Portugal (FCSH-UNL, 1979) - Contributo para uma reflexão acerca do ensino do jornalismo", no âmbito do curso de Ciências da Comunicação - Estudo dos Media e Jornalismo, da Faculdade de Ciências Sociais e Humanas da Universidade Nova de Lisboa; sob a orientação do professor doutor Nelson Traquina e co-orientação da professora doutora Carla Baptista.

${ }^{\text {ii }}$ Antônio de Oliveira Salazar, ditador que governou Portugal entre 1932 e 1968.

iii Nome do regime político autoritário que vigorou em Portugal durante 41 anos, de 1933 até 1974.

iv A palavra tarimba, em seu sentido figurado pode ser interpretada, segundo definição do Dicionário Priberam, como a "preparação ou conhecimento decorrentes de larga experiência em alguma área ou função. = PRÁTICA". http://www.priberam.pt/dlpo/default.aspx?pal=tarimba

${ }^{\vee} \mathrm{O}$ adjetivo tarimbeiro, segundo Dicionário da Língua Portuguesa - Porto Editora, descreve " $\mathbf{2}$ oficial do exército que iniciou a sua carreira como soldado e foi sendo promovido até ao posto de oficial, sem ter feito qualquer curso regular ou frequentado qualquer escola especial; 3 [fig.] que ou que se fez por si; 4 [fig., pej.] que ou o que é grosseiro e rude". Existe uma conotação negativa associada a palavra tarimbeiro.

${ }^{\text {vi }}$ Nome dado ao período em que o ditador Antônio de Oliveira Salazar governou Portugal, entre 1932 e 1968.

vii Em 13 de Setembro de 1976, em assembleia geral, o Sindicato Nacional dos Jornalistas, passa a chamar-se Sindicato dos Jornalistas. in BAPTISTA, Carla (2009) - Apogeu, Morte e Ressurreição da Política nos Jornais Portugueses - do século XXI ao Marcelismo. Lisboa: Tese de Doutoramento em Ciências da Comunicação - FCSH - UNL

viii O jornal Diário Popular simbolizava a vanguarda do jornalismo português.

${ }^{\text {ix }}$ Francisco Pinto Balsemão, à época do Curso de Iniciação Jornalística era secretário de redação, segundo o jornalista Adelino Gomes, em entrevista pessoal de 17/07/10. Atualmente é presidente do grupo de mídia Impresa, detentora da primeira emissora de televisão privada de Portugal, criada em 1992 e de diversos jornais e revistas.

${ }^{\mathrm{x}}$ Revolução dos Cravos, que foi responsável por depor o regime ditatorial em Portugal.

${ }^{x i}$ É o nome dado ao período de ditadura (1968 a 1974) em que Marcelo Caetano governou Portugal.

xii Político fundador do Partido Social Democrata

xiii Professor Catedrático da FCSH, desde 1979. Em 1978, presidiu a Comissão do Ministério da Educação que reorganizou o ensino das ciências sociais nas Universidades Portuguesas. Doutorado pela Université Catholique de Louvain, 1977.

${ }^{\text {xiv }}$ Fundador do Instituto de Ciências Sociais da Universidade de Lisboa.

${ }^{\mathrm{xv}}$ Única mulher que se tornou primeiro-ministro em Portugal, quando chefiou o V Governo Constitucional, de julho de 1979 a janeiro de 1980.

${ }^{\text {xvi }}$ Primeiro presidente da República, democraticamente eleito em Portugal.

xvii Se por um lado o quadro de autogestão contribui para a célere criação da licenciatura em Comunicação Social, a autogestão também diminui a capacidade de decisão e o poder dos professores sobre temas relacionados à instituição. Foi a partir de 1980, que a universidade ganha um director, e que se criam os estatutos e os órgãos de gestão. Segundo entrevista pessoal concedida por Adriano Duarte Rodrigues, em 09/06/10.

Este artigo e todo o conteúdo da Estudos em Jornalismo e Mídia estão disponíveis em http://www.periodicos.ufsc.br/index.php/jornalismo/index

Estudos em Jornalismo e Mídia está sob a Licença Creative Commons. 